\title{
O conflito entre a natureza humana e a condição humana no contexto atual das ciências sociais
}

\section{Conflict between human nature and human condition in the current social sciences context}

\author{
Héctor Ricardo LEIS*
}

A diferença entre Platão e Aristóteles reside em que Aristóteles acreditava na biologia como uma mediação entre o conhecimento das coisas inanimadas e o conhecimento das coisas humanas. Leo Strauss (2000, p. 82)

Quem teria fôlego suficiente para imaginar uma época do mundo em que Nietzsche será tão histórico como Platão o era para Nietzsche? Basta que tenhamos a noção de que as próximas grandes etapas do gênero humano serão períodos de decisão política quanto à espécie. Nelas se revelará se a humanidade

ou suas elites culturais conseguirão pelo menos encaminhar procedimentos efetivos de autodomesticação. Peter Sloterdijk (2000, p. 46)

\begin{abstract}
RESUMO
O conhecimento é marcado por duas culturas distintas: uma que promove a interação entre os diferentes objetos de estudos e outra que os exclui, marcada por especializações e que caracteriza a Modernidade. $\mathrm{O}$ trabalho inter e transdisciplinar sobre problemas preementes do presente momento possibilita romper com essa última perspectiva. Várias são as proposições apresentadas para a sua efetivação, sendo que no presente texto a abordagem ressalta a perspectiva das ciências sociais na construção interdisciplinar do conhecimento. A dimensão ambiental do conhecimento permeia a reflexão aqui elaborada.

Palavras-chave: natureza humana, condição humana, interdisciplinaridade, modernidade, ciências sociais.
\end{abstract}

\footnotetext{
* Professor dos Programas de Pós-Graduação em Sociologia Política e de Pós-Graduação Interdisciplinar em Ciências Humanas, Universidade Federal de Santa Catarina (UFSC). E-mail: < hector.leis@brturbo.com>
} 
LEIS, H. R. O conflito entre a natureza humana e a condição humana...

\begin{abstract}
Knowledge is marked by two different cultures: one promoting interaction among different study-objects and another one that excludes them, is marked by specialized knowledge, and characterizes Modernity. Inter- and trans-disciplinary work on pressing problems of the present day makes it possible to break away from the latter perspective. Several propositions are presented for accomplishing it, and in this text, the approach highlights the social sciences' point-of-view in the interdisciplinary construction of knowledge. Knowledge's environmental dimension permeates the reasoning developed here.

Key-words: human nature, human condition, interdisciplinarity, modernity, social sciences.
\end{abstract}

O conhecimento clássico e medieval não estabelecia nenhuma separação radical entre os vários mundos possíveis que eram objeto de pesquisa e reflexão. Havia sim hierarquias, entre as diversas áreas de conhecimento, mas não hiatos intransponíveis. Independentemente da natureza distinta dos objetos do mundo animal e do mundo político, as bases do conhecimento eram as mesmas. As premissas básicas do conhecimento científico eram comuns e os estudiosos de um ou outro objeto podiam conversar e trocar idéias de forma produtiva. Embora, obviamente existisse uma especialização em torno de cada objeto, a mesma não estabelecia qualquer exclusão ou desinteresse recíproco entre os pesquisadores, do tipo que Snow (1993) encontrou nos anos 50, entre seus colegas das chamadas ciências humanas e exatas da Universidade de Cambridge, o qual o levou a falar de "duas culturas". Se na época de Aristóteles os pesquisadores de diferentes áreas se procuravam para compartilhar seus conhecimentos, se verifica hoje uma tendência geral exatamente contrária, que faz os pesquisadores se entrincheirarem nas suas especialidades ou sub-especialidades, compartilhando seus conhecimentos apenas no interior de um circulo próximo e restrito.

Acredito que essas "duas culturas" (ou como gostemos de chamá-las) estão muito menos separadas por condições ontológicas ou características específicas de seus objetos de pesquisa do que pelas pretensões teóricas e práticas dos próprios pesquisadores. Os preconceitos são mútuos de ambos os lados, porém, obviamente, interessa aqui muito mais tratar dos nossos. O relatório da Comissão Gulbenkian (1996), tão relevante para o aprimoramento das ciências sociais contemporâneas, quanto pouco aproveitado pelas diversas instâncias acadêmicas do mundo, recomenda claramente "abrir as ciências sociais", no sentido de desmantelar as "fronteiras artificiais existentes entre os seres humanos e a natureza", no sentido de reconhecer que as evoluções da sociedade e da natureza fazem parte de um universo único atravessados pelo mesmo vetor do tempo.
No mesmo sentido, o relatório recomenda fortemente o trabalho interdisciplinar e transdisciplinar (nas universidades ou outras instituições de pesquisa) sobre problemas prementes de nossa época, algo que continua sendo pouco atendido por enquanto. Um dos tópicos que o relatório destaca para a pesquisa interdisciplinar se refere, precisamente, à necessidade de refletir de forma conjunta e integrada sobre os modelos sociológicos e biológicos ou, de modo geral, sobre os seres humanos e a natureza, na sua complexidade e inter-relações.

Mas como fazer isso? Os herdeiros de Darwin parecem ter feito seu dever de casa, apresentando um campo de inteligibilidade da evolução natural bastante unificado (Wilson, 1999). Mas não se pode dizer o mesmo das ciências sociais, em geral. Granger (1994) inventaria um mínimo de seis tipos de modelos de inteligibilidade diferentes (além das várias combinações possíveis entre elas) que são usadas normalmente para explicar a dinâmica ou evolução social: 1) causal; 2) funcional; 3) estrutural); 4) hermenêutico; 5) actancial (esquema derivado do comportamento dos atores); e 6) dialético. Granger tira daqui algumas conclusões sumárias sobre as quais as ciências sociais deveriam parar para pensar. Segundo ele, essa pluralidade de esquemas de análise implica a existência de níveis baixos de conceitualização, assim como, sobretudo, uma falta de segurança e até certa arbitrariedade nas explicações oferecidas sobre os fatos sociais e políticos. Acredito que essa fraqueza explicativa não pode ser atribuída a uma certa natureza "intangível" dos fatos humanos, embora certamente exista algo disso. Essa fraqueza está associada basicamente ao reducionismo, uma forte marca de nascença das ciências sociais que as impulsiona na direção contrária à da complexidade, dificultando-as assim para agregar conhecimentos dos fatos humanos vindos de outras disciplinas, muito especialmente da Biologia.

Historicamente, as ciências sociais caracterizaramse por um relacionamento ambivalente com as ciências 
naturais (LEIS, 2001). As teorias da sociedade, do indivíduo e da cultura, predominantes no século XIX, estavam marcadas por fortes influências naturalistas e/ou organicistas importadas das ciências naturais. Os fundadores das ciências sociais modernas construíram seu legado num claro distanciamento com esse passado. Lamentavelmente, os problemas dessa complicada herança foram esquecidos pelos pesquisadores das ciências sociais contemporâneas, os quais tendem a ficar longe das preocupações das ciências naturais, sem perceber quanto essa atitude deriva dos traumas de seu nascimento. Circunstância que, paradoxalmente, contribuiu para que as ciências sociais caminhassem historicamente em direção a um reducionismo que não estava na agenda dos fundadores. A modo de exemplificação dos obstáculos epistemológicos das ciências sociais, revisemos rapidamente as bases teóricas dos fundadores das ciências sociais modernas. Além das diferenças que existem entre Marx, Durkheim e Weber, esses autores construíram modelos de análise que enfatizam a primazia das variáveis sociais, descuidando a importância das variáveis e metáforas vindas das ciências naturais. Não resta dúvidas que Marx, embora aceitando algumas idéias darwinianas, ao enfatizar o proletariado e a base econômica, rejeitou a analogia organicista (que dá igual importância a todas as partes do organismo social). Do mesmo modo, uma das polêmicas mais famosas de Marx foi, precisamente, contra o reducionismo biológico existente na teoria social de Malthus. No caso de Durkheim é também evidente que enfrentou o evolucionismo biologista de Spencer e outros, afirmando que os fenômenos sociais não poderiam ser explicados a partir de variáveis biológicas, como raça, instinto etc. Embora Weber seja um caso mais complexo, também podemos observar que sua principal crítica se dirigiu contra o evolucionismo naturalista de sua época, deixando clara sua posição contra extrapolações metodológicas, de outras esferas para o campo dos fenômenos sociais.

Nessa perspectiva devem ser entendidos os argumentos de Catton e Dunlap (1978) quando, na década dos 70, observaram que todas as teorias clássicas das ciências sociais eram variações de um mesmo paradigma de características socioantropocêntricas. Segundo eles, a ignorância dessa matriz comum levou às diversas gerações de cientistas sociais a exagerar as diferenças entre os vários esquemas de inteligibilidade propostos para explicar a dinâmica ou evolução social (tal como vimos acima). Uma conseqüência impensada desse reducionismo fragmentado foi a de facilitar o caminho das ciências sociais na direção do senso comum da sociedade. De algum modo, as ciências sociais, ao perderem vigor científico, ficaram mais expostas a serem "capturadas" pelos projetos e desejos dos atores sociais. E, inversamente, quanto mais as ciências sociais procuraram transformar a realidade de acordo com as demandas dos atores da sociedade civil, maior foi seu abandono de um trabalho verdadeiramente científico.

Os fatores apontados levaram as ciências sociais a abordar seus objetos de estudo deixando entre parênteses suas concepções de natureza e, em particular, de natureza humana. Assim, com poucas exceções, os cientistas sociais arrepiam os cabelos quando ouvem falar da hipótese da existência de uma natureza humana. Quase que reivindicando o relato do Gênese, em que os primeiros seres humanos são violentamente colocados para fora da natureza e condenados a depender exclusivamente de seus próprios esforços, vivendo em sociedade, as ciências sociais pretendem substituir ou transformar a natureza humana em um construto ao gosto dos atores sociais. Porém, para salvar as aparências e deixar em claro que elas são disciplinas secularizadas, invertem o mito do Gênese num aspecto essencial. Se na mensagem bíblica a sociedade aparecia ligada indissociavelmente à "queda" do Paraíso, para as ciências sociais agora será o inverso. Se na Bíblia a salvação está fora da sociedade, para elas a salvação estará dentro, elas nos induzem a pensar que a sociedade é progressivamente boa e que a natureza é apenas um obstáculo a ser superado no caminho do aperfeiçoamento social. Assim sendo, os seres humanos teriam tudo a ganhar esquecendo sua natureza humana e concentrando-se com otimismo na transformação dos aspectos sociais de sua condição humana.

Mas o conhecimento científico não autoriza ninguém a ser otimista ou pessimista em relação ao significado extracientífico de seus fatos (LEIS, 2000). Se duas galáxias colidem, ainda que com isso sejam hipoteticamente destruídos milhões de mundos como o nosso, os astrofísicos certamente não ficam nem mais deprimidos, nem mais alegres. Se as ciências naturais descobrem uma intimidade insuspeita entre os humanos e alguns primatas, isso também não autoriza ninguém a ser mais ou menos pessimista. Max Weber nos lembra que na atividade científica não estão em jogo as conseqüências para os seres humanos derivadas dos avanços do conhecimento, embora esses avanços possam trazer-lhes alegrias ou tristezas. O que está em jogo, precisamente, é o próprio avanço do conhecimento científico. Por isso, os únicos sentimentos permitidos na ciência dizem respeito aos avanços ou retrocessos do co- 
nhecimento como tal. Que significa então a necessidade de serem otimistas que exibem a maioria dos cientistas sociais em suas reflexões e análises?

Embora esse otimismo não seja generalizável, ele é um derivado do reducionismo e fragmentação das ciências sociais. Ainda quando existem autores como Pareto, Foucault ou Luhmann (para citar alguns dos mais destacados), que não encorajam seus leitores a verem as sociedades modernas como lugares de salvação, a maioria dos cientistas sociais se sente mais confortável ao lado de autores clássicos como Marx e Durkheim, ou de seus discípulos contemporâneos, como Giddens e Habermas, para os quais o mundo social é muito mais o resultado da ação de atores ou sujeitos conscientes e/ou de forças sobre as quais estes exercem algum tipo de controle. É por esse caminho que as ciências sociais se confundem com o senso comum. Os cientistas sociais que neutralizam ou descaracterizam a importância da natureza humana para compreender a vida social não percebem que seu reducionismo os impede de ver que os resultados de seus trabalhos derivam mais do senso comum que da própria ciência. Pelos mesmos motivos também não percebem a necessidade de reabrir urgentemente o debate sobre os antecedentes e estatuto científico das ciências sociais. Quando pouco após o fim da Segunda Guerra Mundial emergiram os problemas ambientais e os cientistas sociais deixaram os biólogos quase falando sozinhos sobre a crise ecológica, tivemos uma prova das dificuldades dos primeiros para lidar com questões interdisciplinares de amplo espectro e, em particular, para relacionar-se com os trabalhos dos segundos. Isso se traduziu numa fraqueza histórica considerável do debate ambientalista, que ficou durante décadas sujeito a simplificações (que, em parte, ainda continuam) por conta de centrar-se quase exclusivamente na análise de variáveis naturais. Porém, ainda que os problemas ambientais tenham um forte impacto sobre a sociedade, não vai ser possível compará-los com o impacto que terá no futuro próximo a engenharia genética e a questão biotecnológica, de modo geral.

Sabendo do "gosto" do senso comum pela diversidade de opiniões, não pode ser uma surpresa então que os avanços teóricos das ciências sociais, nas últimas décadas, resgataram fortemente o valor da diversidade e da diferen- cia. Mas hoje temos provas irrefutáveis de que além das diversidades das sociedades, das culturas e das épocas, os seres humanos compartilham uma natureza humana que é fonte comum de comportamentos, atitudes e motivações (DORTIER, 2003). Essa singularidade da natureza humana, para além das diversidades e diferenças, é mais um indicador das dificuldades que as ciências sociais teriam para revisar sua marcha atual (INGOLD, 1995). Além da genética, a psicologia evolutiva é o campo de pesquisa que atualmente concentra maior quantidade de estudos empíricos que colocam em evidência a singularidade da natureza humana. O campo da psicologia evolutiva deve muito ao antropólogo Tooby e a psicóloga Cosmides (ver seu ensaio, "The Psychological Foundations of Culture”, 1992). Numa linha convergente com as críticas vindas do lado ambientalista, esses autores argumentam que os modelos explicativos dominantes nas ciências sociais impedem, precisamente, de fazer a ponte com a teoria da evolução derivada dos trabalhos de Darwin. Cosmides e Tooby negam o senso comum vigente que pretende que os seres humanos nasçam sem qualquer instrução congênita, codificada na sua natureza, e que sejam moldados apenas pelo ambiente e pela educação. Na opinião deles, a incapacidade das ciências humanas e sociais para se aproveitarem dos descobrimentos da biologia está associada à crença de que a cultura é a única "natureza humana" existente (crença plenamente reforçada no senso comum emergente nos anos $60 \mathrm{e}$ 70, que definiu como "politicamente correto" evitar qualquer contaminação com "preconceitos" biologicistas).

Não interessa aqui desenvolver os trabalhos existentes na psicologia evolutiva sobre os repertórios de "programas" cognitivos e emocionais que os seres humanos carregam no cérebro, associados a problemáticas tão relevantes quanto as das emoções relativas à sexualidade, à família, à cooperação, à violência, à inteligência, à religião, à cultura e à linguagem. ${ }^{1}$ Interessa muito mais colocar em evidência os argumentos defensivos e, em geral, o anacronismo das ciências sociais. Seja na perspectiva de aprimorar nossos espíritos ou não, na hora de pensar as instituições sociais e políticas, as ciências sociais não podem prescindir de uma análise realista da natureza humana. Mas como julgar as instituições existentes ou imaginar outras novas se nos negamos a reconhecer a natureza humana como um dado

1 Em relação à problemática da linguagem resulta difícil não registrar a curiosidade de ter sido um autor politicamente correto, como Noam Chomsky, o primeiro a afirmar que as regras de gramática são uma aptidão inata da espécie humana (ver: PINKER, 1994). 
verificável e pesquisável da realidade? Por incrível que pareça, os aspectos centrais de nossos princípios e instituições políticos e sociais atuais foram definidos, entre os séculos XVII e XIX, por um amplo espectro de pensadores (Hobbes, Locke, Rousseau, Kant, Montesquieu, Hegel, Marx, Stuart Mill etc.) fortemente condicionados pelas concepções da natureza humana disponíveis na época. Isso supõe um belo qüiproquó, já que as ciências sociais, embora sendo reducionistas para o social, de um modo geral continuam ainda prestigiando as instituições imaginadas por autores associados a concepções quase mitológicas da natureza humana. Não será então que a partir dos conhecimentos produzidos na última década (e a serem produzidos ao longo do século XXI) pela biologia, em geral, e pela psicologia evolutiva, em particular, deveríamos repensar nossas idéias tradicionais sobre as instituições da sociedade e do Estado?

As ciências sociais contemporâneas não podem ficar "em cima do muro", criticando com argumentos morais os descobrimentos científicos e possibilidades tecnológicas que recolocaram, no final do século XX, a questão da natureza humana no centro do cenário. Na medida que as conseqüências para a história da humanidade são de grande impacto, a resistência para entrar com força no debate aberto pela atual revolução biológica parece injustificável. Em relação à nossa espécie, a revolução biológica torna possíveis transformações eugénicas inimagináveis no passado recente. A velha eugenia justifica plenamente os preconceitos dos cientistas sociais. Seus defensores de fim de século XIX e primeiras décadas dos XX (os quais não foram poucos e se encontravam em todos os países ocidentais) estavam guiados muito mais pelos preconceitos do que pela pesquisa científica (KEVLES, 1997). As correntes dominantes da velha eugenia maquiavam com palavras científicas propostas profundamente discriminatórias no plano comportamental, racial e religioso. Mas a nova eugenia guarda distâncias enormes com a anterior, para começar nem aparece identificada com esse nome. A eugenia do século XXI se apresenta despolitizada, sem nenhuma vinculação com qualquer preconceito racial ou religioso. Também não é o Estado que a impulsiona, como no caso anterior. A nova eugenia chega impulsionada pelas pesquisas dos cientistas e pelos desejos das pessoas de evitar doenças e melhorar suas capacidades físicas e mentais.

Os alcances individuais da engenharia genética poderão, eventualmente, ser decididos reflexivamente (GIDDENS) ou comunicativamente (HABERMAS), mas o alcan- ce global da mesma simplesmente vai acontecer acompanhando a ação sistêmica da produção de conhecimento e do lançamento de novas tecnologias no mercado. Assim como ninguém pensa hoje que seria viável fazer uma campanha para fechar todas as clínicas e hospitais privados do mundo, de modo a garantir a todos igual acesso à saúde por meio de instituições públicas, também não terá viabilidade qualquer campanha pública contra os benesses da nova eugenia. Ainda que seja difícil saber quais seriam os melhores caminhos para a evolução humana, não restam dúvidas de que na atual modernidade, nem a moralidade nem a política podem ser imaginadas em oposição frontal ao desenvolvimento da ciência e da tecnologia. As ciências sociais não podem então desconhecer a urgência das questões latentes na modernidade técnica atual. Essas questões poderiam ser provisoriamente organizadas em torno do seguinte dilema: o que é mais importante para o desenvolvimento da humanidade, a evolução dos indivíduos como espécie (entendendo isso basicamente como um melhor desenvolvimento das condições genéticas dos indivíduos) ou a evolução dos indivíduos como sociedade?

Uma coisa significativa a ser registrada, que se produz sempre com o impacto de questões de ordem biológica no debate público, é que os velhos conflitos entre esquerda e direita tendem a dissolver-se. Isso aconteceu com o debate sobre a eugenia no início do século XX, quando o divisor de águas de esquerda e direita não operava, havendo defensores dessa concepção tanto de um lado como de outro. Do mesmo modo, a partir do reconhecimento da existência de uma natureza humana, encontramos hoje autores como Singer (1999) argumentando que a perspectiva darwiniana é perfeitamente conciliável com o pensamento de esquerda, ao lado de outros como Masters (1989) e Arnhart (1998) argumentando numa direção contrária, que a perspectiva darwiniana é perfeitamente funcional com o conservadorismo aristotélico. Insisto que não interessa tanto discutir e/ou tomar partido entre os escassos autores que aceitam incluir no debate das ciências sociais a questão da natureza humana, senão interessa especialmente entender os argumentos daqueles que se excluem desse debate. Como já foi dito antes, a crítica desses últimos (que aliás, como sabemos, representam a maioria dos cientistas sociais) coloca melhor à luz os obstáculos epistemológicos a serem vencidos para uma aproximação entre as ciências sociais e as biológicas no atual momento.

Nesse sentido, talvez ninguém melhor que um autor como Habermas, tão representativo das ciências sociais contemporâneas, para colocar em evidência esses obstácu- 
los. Como forma de preservar a dignidade e autonomia humana, recentemente Habermas se manifestou contrário a manipulações e/ou ao conhecimento da condição genética dos seres humanos (HABERMAS, 2003). ${ }^{2}$ Resulta não menos que curiosa essa pretensão habermasiana de querer proteger a "natureza humana", especialmente se consideramos que ele nunca se interessou pelo tema nem lhe deu qualquer espaço significativo dentro de sua obra. Querer preservar a natureza humana à custa de nossa ignorância (a qual supõe não querer saber, nem querer corrigir, patologias herdadas geneticamente, por exemplo) não é apenas uma demonstração de anti-realismo bizarro, mas também do forte reducionismo, que escondem na sua bagagem os cientistas sociais. Como forma de manter intacta nossa dignidade, o contratualista Rousseau imaginava que nossa natureza humana não tinha nada de errado. Agora que começamos a descobrir as coisas que tem de errado, Habermas nos quer convencer a manter "intacta" nossa ignorância. Concordo com Zizek (2003) quando critica Habermas, por preferir a ignorância ao risco. Mas tem ainda muito mais coisas envolvidas nas resistências habermasianas ao conhecimento.

Segundo Zizek, a resistência de Habermas ao conhecimento específico de nossa natureza humana (que eu acho representativo do medo da maioria dos cientistas sociais) se expressa como resistência a ter que enfrentar a redefinição das noções éticas vigentes de liberdade, autonomia, responsabilidade etc. É obvio que isso se torna necessário, mas minha questão aqui não é tanto ética como ontológica e epistemológica. A questão não é primariamente ética porque o que está em jogo é o lugar a partir do qual se pensa a condição humana. O conhecimento científico (embora bastante parcial) de nossa natureza humana anuncia uma nova revolução copernicana que tira ao indivíduo-social do centro do "sistema solar". Ainda acreditando-se copernicanos, os cientistas sociais são ptolomeicos, na medida que, de um modo ou outro, privilegiam a relação indivíduo-sociedade como eixo em torno do qual gira a história humana. Os avanços contemporâneos da biologia não apenas obrigam a redefinir a ética, tirando-a do anacronismo socrático-kantiano de pensar o indivíduo-social como medida de todas as coisas, mas obrigam a redefinir também os fundamentos das ciências sociais colocando à espécie como um protagonista privilegiado da história humana. Em outras palavras, se aceitamos o desafio da biologia contemporânea temos que abandonar o universalismo construído a partir da categoria de indivíduo, como membro da sociedade, para entrar num outro universalismo (de complexidade superior) construído a partir de um indivíduo pensado simultaneamente como membro da sociedade e da natureza. Certamente isso implica ir além o que Jonas (1995) propôs, por exemplo, faz duas décadas (de ampliar a tradicional responsabilidade dos atos humanos, incluindo a natureza), já que ele continuava ainda pensando em termos de preservar o futuro de gerações que continuariam sendo biologicamente iguais às atuais. $\mathrm{O}$ desafio, seja dito mais uma vez, reside em pensar a evolução da sociedade tanto quanto da espécie humana.

Vale a comparação de dizer que as resistências de autores como Habermas ou Fukuyama estão aparentadas com as dos psicanalistas frente aos antidepressivos. Concordo com os psicanalistas que níveis altos de serotonina não garantem, obviamente, níveis altos de reconhecimento. Mas o tema do Prozac não é de pouca monta, a questão que levantam os psicanalistas e os cientistas sociais (e também os bio-éticos) deriva de seu reducionismo. Suas defesas múltiplas e variadas da "dignidade" da natureza humana não são por acaso. A questão que as ciências biológicas estão hoje colocando em evidência é que todos os reducionismos no campo das ciências humanas e sociais supõem uma sacralização do humano, em que o humano é entendido de forma anti-realista a partir das categorias do Iluminismo. O que ameaça aos psicanalistas e cientistas sociais, em geral, é a perda da ilusão do humanismo iluminista. Eles preferem jogar a criança com a água junto, antes de reconhecer que a criança está jogada na aventura da vida também como espécie e que, portanto, o humanismo iluminista não é o único "humanismo" possível. O dilema apresentado antes, entre a evolução dos indivíduos como espécie e a evolução dos indivíduos como sociedade, não deixa de ser também um dilema humanista perfeitamente datado. O dilema surge apenas quando pretendemos congelar a história da humanidade a partir de uma certa visão do humano e, portanto, da natureza humana. Se nos animássemos a tirar os seres humanos da gaiola dos reducionismos das ciências sociais e, em conseqüência, a

2 Mais uma vez, a divisão entre esquerda e direita não funciona aqui, esta visão "protecionista" se encontra tanto em um cientista social de esquerda como Habermas, como em outro mais conservador, como Fukyama (ver: zIZEK, 2003). 
pensá-los também como protagonistas de uma história como espécie, o dilema se dissolveria rapidamente.

Prevendo algum mal-entendido, me antecipo a dizer, para finalizar, que não vejo que minha posição induza à supressão da ética, simplesmente estou pedindo o alargamento do pensamento em relação à espécie humana. Os motivos para proteger os seres humanos deles mesmos existem desde o início da história e vão conti- nuar existindo no futuro, e isso certamente garante um lugar para a ética. Mas desconheço que exista algo que fique mais longe das possibilidades do senso comum que pensar a espécie humana de um modo conseqüente. A primeira tarefa para que a aproximação entre as ciências sociais e as biológicas seja hoje possível parece ser então cortar os laços que as primeiras têm com o senso comum.

\section{REFERÊNCIAS}

ARNHART, Larry. Darwinian Natural Right: The Biological Ethics of Human Nature. Albany: Suny, 1998.

CATTON Jr., W. R.; DUNLAP, R. E. Environmental Sociology: A New Paradigm? The American Sociologist, v. 13, 1978.

COMTE-SPONVILLE, André; FERRY, Luc. A sabedoria dos modernos. São Paulo: Martins Fontes, 1999.

COSMIDES, Leda; TOOBY, John. The Psychological Foundations of Culture. In: BARKOW, J. H. L.; COSMIDES, Leda; TOOBY, John. (Orgs.). The Adapted Mind. Nova York: Oxford University Press, 1992.

DORTIER, Jean-François. La nature humaine redécouverte. Sciences Humaines, n. 139, 2003.

GRANGER, Gilles-Gaston. A ciência e as ciências. São Paulo: Unesp, 1994.

GULBENKIAN, Comissão. Para abrir as ciências sociais. São Paulo: Cortez, 1996.

HABERMAS, Jurgen. The Future of Human Nature. Cambridge: Polity Press, 2003.

INGOLD, Tim. Humanidade e animalidade. Revista Brasileira de Ciências Sociais, n. 28, ano 10, 1995.

JONAS, Hans. El Principio de Responsabilidad. Barcelona: Herder, 1995.

KEVLES, Daniel J. In the name of Eugenics. Cambridge: Harvard University Press, 1997.
LEIS, Héctor Ricardo. A modernidade insustentável: as críticas do ambientalismo à sociedade contemporânea. Petrópolis: Vozes, 1999.

A tristeza de ser sociólogo no século XXI. Dados, v. 43, n. 4, 2000.

Para uma reestruturação interdisciplinar das ciências sociais. Ambiente e Sociedade, ano 4, n. 8, 2001.

MASTERS, Roger D. The nature of politics. New Haven: Yale University Press, 1989.

PINKER, Steven. The language instinct; the new science of language and mind. Londres: Penguin, 1994.

SINGER, Peter. A Darwinian left. Londres: Yale University Press, 1999.

SLOTERDIJK, Peter. Regras para o parque humano. São Paulo: Estação Liberdade, 2000.

SNOW, C. P. The two cultures. Cambridge: Cambridge University Press, 1993.

STRAUSS, Leo. On tyranny. Chicago: University of Chicago Press, 2000.

WILSON, Edward O. On human nature. Cambridge: Harvard University Press, 1978. 1999.

. A unidade do conhecimento. Rio de Janeiro: Campus,

ZIZEK, Slavoj. A falha da bio-ética. Folha de S. Paulo, Caderno Mais!, 22 jun. 2003. 